\title{
Sentimental preferences and the organizational regime of betting markets
}

\author{
Franck, Egon ; Verbeek, Erwin ; Nüesch, Stephan
}

DOI: https://doi.org/10.4284/0038-4038-78.2.502

Posted at the Zurich Open Repository and Archive, University of Zurich ZORA URL: https://doi.org/10.5167/uzh-52562

Journal Article

Published Version

Originally published at:

Franck, Egon; Verbeek, Erwin; Nüesch, Stephan (2011). Sentimental preferences and the organizational regime of betting markets. Southern Economic Journal, 78(2):502-518.

DOI: https://doi.org/10.4284/0038-4038-78.2.502 


\title{
Sentimental Preferences and the Organizational Regime of Betting Markets
}

\author{
Egon Franck,* Erwin Verbeek, $\dagger$ and Stephan Nüesch $\ddagger$
}

\begin{abstract}
We analyze the price impact of sentimental bettor preferences within a bookmaker betting market. A theoretical model demonstrates that, under reasonable assumptions about the nature of demand in a market with strong competition, the bookmaker will offer lower prices for bets with comparatively stronger demand. Using a sample of more than 16,000 English soccer matches we find evidence that more favorable odds are extended to bets on more popular clubs and that this effect is amplified on weekends when sentimental bettors face lower opportunity costs to wager. Our findings help to explain why the market for sports gambling operates as a hybrid structure with bookmakers able to attract a considerable share of the betting volume, although identical contracts are traded on exchange markets at lower costs: the organizational design of a quote-driven market enables the dealer to take advantage of sentimental bettor preferences.
\end{abstract}

JEL Classification: D40, G13, G14

\section{Introduction}

There are a variety of different institutional regimes in which options contingent on the outcome of future events can be traded. At the beginning of the $1990 \mathrm{~s}$, markets for financial products relied mainly on a quote-driven mechanism. Here, the so-called specialist acts as a dealer and intermediates between buyers and sellers by unilaterally determining the prices on a given contract. NASDAQ and the London Stock Exchange were, at that time, two leading examples of such a trading structure. Since then, order-driven systems have become more prevalent. Essentially this organizational setting involves a platform on which a double-auction process between individual traders is enabled. An investor has the choice to submit a limit order and wait for another participant to hit his quote, or alternatively, he can submit a market order matching an already offered quote. Most financial markets have now adopted either a pure limit order book or a mixed structure in which both market mechanisms coexist. On the $N A S D A Q$ or the New York Stock Exchange, for example, orders from the public compete with

* University of Zurich, Institute for Strategy and Business Economics, Plattenstrasse 14, 8032 Zurich; E-mail egon.franck@business.uzh.ch.

$\dagger$ University of Zurich, Institute for Strategy and Business Economics, Plattenstrasse 14, 8032 Zurich; Phone: +41 4463429 61; E-mail erwin.verbeek@business.uzh.ch; corresponding author.

‡ University of Zurich, Institute for Strategy and Business Economics, Plattenstrasse 14, 8032 Zurich; E-mail stephan.nuesch@business.uzh.ch.

We would like to thank the editor, Laura Razzolini, and two anonymous referees for their helpful suggestions. We also thank David Forrest and other participants at the conference "The Economics and Psychology in Football," 2008, in Innsbruck for their valuable comments. Marc Brechot, Angelo Candreia, and Nicolai Grüter provided excellent research assistance. This article was partly written while Erwin Verbeek was visiting the Haas School of Business, University of California at Berkeley. Special thanks go to Steven Tadelis and his staff for their hospitality. This article is based on a chapter of the second author's 2009 dissertation.

Received September 2010; Accepted November 2010. 
dealer quotes (see, e.g., Schwartz and Weber 1997; Madhavan 2000; Marshall and Young 2003).

Similar to financial markets, the sports-betting industry also involves different organizational systems. In Great Britain gambling has traditionally been designed as a parimutual or totalisator system. Here, the payout ratio of a winning bet is calculated by sharing the pool among all winning bets reduced by the totalisator's commission. An apparent drawback of this procedure is that the payout ratio is not determined ex ante because it depends on the final betting volume placed on a given outcome relative to the overall pool. Consequently the pari-mutual system has partly been replaced by fixed-odds mechanisms in which the bettor's claim is tied to the initially taken odds and does not depend on subsequent price changes. Bookmaker markets have become the dominant form of gambling on team sports in the United States, in the UK, and in many other Commonwealth countries in general (Forrest and Simmons 2001). Similar to the specialist in a quote-driven market setting, the bookmaker acts as a dealer announcing the prices against which the bettors can place their bets. ${ }^{1}$ In recent years person-to-person exchange betting has evolved as a third-market mechanism. Here, as in the order-driven setting of financial markets, it is not the dealer but another individual trader taking the opposite side of a contract.

In the gambling industry the different organizational structures coexist and compete with each other to attract order flow. In sports betting, for example, traditional bookmakers (such as Ladbrokes, William Hill, Interwetten among others) and emerging bet exchanges (such as Betfair or World Bet Exchange among others) provide the opportunity to place bets on the very same event. The obvious appeal of the order-driven mechanism is that the market operator's revenues are independent of the specific game outcome. Bet exchanges simply provide an electronic trading platform and claim their commission fee on every transaction being processed between two bettors. Meanwhile, traditional bookmakers are exposed to substantial risk as they take the contrary position of every wager being placed. Therefore, bookmakers need to calculate their postings by using costly forecasting models, which have to be continuously updated for new information reaching the market as well as for the incoming order flow from the bettor's side. Thus, not surprisingly, bet exchanges offer more favorable odds than bookmakers on average (e.g., Koning and van Velzen 2009; Franck, Verbeek, and Nüesch 2010a). It is, therefore, puzzling that the market for sports gambling operates as a hybrid structure with bookmakers able to attract a considerable share of the betting volume although identical contracts are traded elsewhere at lower costs. How have bookmakers remained competitive against rival order-driven market forms? More specifically: What is the benefit of actively managing quotes compared to passively matching supply and demand?

The survey article of Madhavan (2000) names some reasons for the coexistence of an order-driven and quote-driven market offering the same fundamentals. He argues that dealers may be valuable to the market as they help to discover and stabilize prices and provide liquidity. A further explanation for the coexistence of bookmakers and order-driven systems in betting markets, explicit in Levitt (2004) and implicit elsewhere (e.g., Kuypers 2000; Bruce and Johnson 2005; Chung and Hwang 2010; Franck, Verbeek, and Nüesch 2010a), is that the organizational design of a dealer market facilitates exploitation of sentimental bettor

\footnotetext{
${ }^{1}$ In Europe these prices typically represent the payout ratio of a winning bet, whereas in the United States these prices are translated into a point spread by which the victorious team needs to beat the opponent for a bet to pay out a fixed ratio of the stake wagered.
} 
preferences. These studies argue that bookmakers are able to take advantage of sentimental bettor perceptions by posting that which deviate from efficient prices. Betting volume is expected to spread equally across all possible outcomes of a certain event if prices represent the implicit true probabilities. If, however, bettors prefer options with a particular characteristic and, as a result, stronger demand goes to one of the outcomes, then bettors' perceptions are seen to be sentiment driven. Under the modeling of Kuypers (2000) and Levitt (2004) the bookmakers can earn higher profits by increasing the price (deteriorating the odds or posting higher point spreads, respectively) on more heavily demanded bets.

Although intuitive, we demonstrate that this result relies on rather strong assumptions about the nature of the demand an individual bookmaker is facing. The shape of an individual bookmaker's demand function, in turn, reflects the market's competitive situation: The stronger the competition, the more sensitively demand will react to the bookmaker's pricing decision. In the models of Kuypers (2000) and Levitt (2004) the overall betting volume on a given match is exogenously given, and only the fraction of the overall volume placed on an outcome is influenced by the preferences of the bettors and the bookmaker's price setting. This corresponds to a situation where bettors, at first, decide whether at all to bet on a given match with a particular bookmaker and, thereafter, they choose on which outcome to place their bets. This simplification may be consistent with the market environment in the United States, ${ }^{2}$ where regulative interventions have created a quasi-monopoly for sports betting. ${ }^{3}$ The model assumption of one bookmaker that sets prices, however, does not meet the apparent conditions of European sports betting, where the market is highly competitive. Several bookmakers post their odds on the very same event, thus offering a quasi-perfect substitute to the betting audience. Especially in online gambling, bettors can easily compare the odds of various bookmakers and identify the most favorable prices at low-searching costs, for example on websites such as www.betexplorer.com or www.oddschecker.com. Moreover, the assumptions do not take into account that the bookmakers compete with bet exchanges, where prices are the result of matching a multitude of individuals with opposing opinions.

Our model relaxes the assumption of a closed-form demand structure. Instead of arbitrarily determining that the bettor's decision to place a bet with a given bookmaker is already taken, we endogenize the overall betting volume as a function of the bookmaker's price setting decision. We demonstrate that whether it is optimal to increase or decrease the price on more heavily demanded bets depends on the elasticity of demand an individual bookmaker is facing and how it is influenced by bettor sentiment. In the case of strong competition as in the European online betting market, bookmakers are likely to operate in the area of elastic individual demand. ${ }^{4}$ It is reasonable to assume that at least a fraction of the sentiment bettors do compare the terms offered by different bookmakers before placing their bets. The model

\footnotetext{
${ }^{2}$ In fact Levitt (2004) analyzes bookmaker prices for National Football League (NFL) matches and finds evidence consistent with his theoretical predictions: Prices are less favorable for bets with comparably stronger demand-in his case, bets on favorites to win the game.

${ }^{3}$ Nevada is the only state in the United States with legalized sports betting. Even though there are over a hundred licensed sports books in Nevada, most of the sports books use the same odds-setting agency so that shopping around for better odds is difficult (Forrest and Simmons 2008).

${ }^{4}$ The elasticity of a bookmaker's individual demand is not infinite, however, as the betting market is found to be imperfectly competitive. This is supported by the fact that prices on the very same options vary across bookmakers (e.g., Pope and Peel 1989; Vlastakis, Dotsis, and Markellos 2009) and across market mechanisms (e.g., Smith, Paton, and Vaughan Williams 2006, 2009; Franck, Verbeek, and Nüesch 2010a, b).
} 
shows that, under these conditions, it can be optimal for the bookmaker to decrease the price (improve the odds) for more heavily demanded bets rather than increasing it.

In the empirical part of this article we investigate the price effect of team popularity as one source of sentimental betting. Because the betting volumes wagered at different bookmakers are a well-kept secret, we focus on sentiment betting that can be systematically linked to observable characteristics. This comes at the cost that we are only able to examine "the tip of the iceberg." Bookmakers are expected to not only exploit systematic demand shifts but also unsystematic shifts, for they continuously observe the incoming demand and will, therefore, react to it in either case to maximize their profits. Yet the price impact we are after is predictable ex ante as a team's popularity is readily available information. Therefore, the significance of any price effect found in our sample is even more striking as it represents a market inefficiency deliberately provoked by the bookmakers.

The popularity of a team as a source of sentimental betting and market inefficiency has been documented in the recent literature (e.g., Avery and Chevalier 1999; Braun and Kvasnicka 2008; Forrest and Simmons 2008). These studies argue that there might be some "committed" bettors who feel the urge to demonstrate their loyalty to a particular club by wagering their money on it. ${ }^{5}$ More glamorous teams have a larger fan base and are, therefore, more prone to attracting sentiment bets. In essence there is ceteris paribus an excessive proportion of stakes placed on the relatively more popular team winning. The empirical evidence on the direction to which bookmakers shade prices in the presence of sentiment is mixed. Avery and Chevalier (1999) show that winnings from backing prestigious teams in the National Football League (NFL) were abnormally low. Forrest and Simmons (2008) find that in Spanish and Scottish soccer leagues not less but more favorable odds are offered for bets on more popular teams. Braun and Kvasnicka (2008) investigate the odds of different bookmakers for qualification games to the UEFA Euro 2008 and present evidence that some bookmakers shade prices in favor of the corresponding national team, and others shade prices against it.

We analyze the price setting of eight well-known bookmakers for more than 16,000 English soccer matches played in the 2000-2001 to 2007-2008 seasons. We use the average home attendance as proxy for the amount of sentiment bets attributable to team popularity. In line with the predictions of our theoretical model and given the assumptions about the nature of demand in the English football betting market, we find evidence that bookmakers offer more favorable prices for bets on more popular teams.

But this result could yet have an alternative explanation. Shin $(1991,1992,1993)$ has pointed out that bookmakers may shade the odds in order to hedge against the threat of bettors endowed with superior information. According to this theory, bookmakers lower the high odds on underdog teams where the risk of insider knowledge is particularly harmful. The empirical consequence of this reasoning is the favorite longshot bias [see, e.g., the review of Coleman (2004)], which describes the well-documented empirical regularity that bookmaker odds tend to underestimate (overestimate) the frequency of high (low) probability outcomes. Since more popular teams are mainly the ones with stronger playing talent, the positive correlation between the fan-base and the expected betting return could be driven by aspects related to the longshot

\footnotetext{
${ }^{5}$ Even though behaving as if they had misperceptions, sentiment bettors might be capable of assessing win probabilities objectively. They are only biased in the sense that they exhibit a preference for betting on a particular outcome. Whether this behavior implies irrationality depends on the prices sentiment bettors are willing to accept when they place their bets.
} 
bias. In order to rule out the longshot bias as an alternative explanation, we distinguish between weekday and weekend games. Because every team in a league is randomly assigned the same number of weekday matches, this third variable is independent of which teams are involved in the match. Within the Shin model only the match composition should determine to what extent the bookmaker shades his prices because bettors endowed with superior information are as likely on weekdays as on weekends. Casual bettors who are susceptible to different kinds of sentiment, however, are more likely to place bets on weekends compared to weekdays (Kopelman and Minkin 1991; Sobel and Raines 2003; Sung and Johnson 2009). Consistent with the theoretical prediction, we find clear evidence that more favorable prices are extended to bets on more popular clubs winning, and that this effect is amplified on weekend games when the fraction of sentiment-driven bettors is expected to be higher.

Our results indicate that bookmakers actively shade prices in order to exploit sentimental preferences of the betting audience: They offer competitive odds where demand is relatively strong. We argue that, at least partly, it is due to the active pricing policy illustrated here that bookmakers have been able to remain profitable against rival order-driven structures that passively match supply and demand and operate at lower cost levels.

The remainder of the article is structured as follows. Section 2 provides the theoretical model of the bookmaker's price setting decision in the presence of sentiment betting. Section 3 presents the empirical findings, and section 4 concludes.

\section{The Theoretical Model}

Our model explores the price-setting behavior of a risk-neutral profit-maximizing bookmaker. In a soccer match there are three possible outcomes $e \in\{H, D, A\}$ : a home win, a draw, and an away win. The bookmaker posts the decimal odds $o_{e}$, which represent the payout ratio for a winning bet. We refer to $\hat{p}_{e}=1 / o_{e}$ as the bookmaker's probability odds offered to the betting audience. ${ }^{6}$ By $\varphi_{e}$, we denote the true probability for an outcome $e$ happening. ${ }^{7}$

The bookmaker's per match profit is given by the volume wagered on the outcomes $v_{e}$ minus the corresponding expected payout to the bettors:

$$
E[\Omega]=v_{H}\left[1-\frac{\varphi_{H}}{\hat{p}_{H}}\right]+v_{D}\left[1-\frac{\varphi_{D}}{\hat{p}_{D}}\right]+v_{A}\left[1-\frac{\varphi_{A}}{\hat{p}_{A}}\right] .
$$

In other words we sum up the amount of money wagered times the expected profit margin (denoted by the expression in brackets) for each outcome of a match.

The bettor's average return on a one-unit bet is given by $\varphi_{e} / \hat{p}_{e}$. The bookmaker's probability odds of a match $\hat{p}_{e}$ sum to greater than one because of the inherent over-round $s$, so that $\hat{p}_{H}+\hat{p}_{D}+\hat{p}_{A}=1+s$. Hence, the bettor's payout ratio on a randomly chosen bet is $E\left[\varphi_{e} / \hat{p}_{e}\right]=1-s^{8}$

\footnotetext{
${ }^{6}$ From the bettor's point of view a bet is profitable in expectation whenever he estimates the outcome to occur more often than the reciprocal of the odds.

${ }^{7}$ We state that the bookmaker is likely to be more skilled in predicting the match outcome than any other party. Thus, any deviation from average pricing can be seen as an intentional act from the bookmaker's side rather than a failure in processing relevant information into the odds.

${ }^{8}$ The bettor earns the same return if he wagers on all three outcomes of the match, spreading the stake relative to the bookmaker's probabilities.
} 
On average the bookmaker's profit margin $\left[1-\left(\varphi_{e} / \hat{p}_{e}\right)\right]$ equals $s$. In the following we assume that the bookmaker prices the bet on a tie game such that $\left[1-\left(\varphi_{D} / \hat{p}_{D}\right)\right]=s$. This assumption is in line with the empirical regularity in soccer that draws appear to be almost random events (Dobson and Goddard 2001). To keep the model simple, we assume that $s$ is fixed across matches. Hence, the bookmaker is left with only the decision of how to price bets on home wins against away wins. To simplify matters, we can thus drop draw bets and Equation 1 reduces to

$$
E[\Omega]=v_{H}[s-d s]+v_{A}[s+d s] .
$$

The bookmaker can either increase the price of bets on the home team winning and decrease the price of the away win bets or vice versa. Recall that the price $s_{e}=[s \pm d s]$ refers to the bookmaker's decision of how to choose the odd $o_{e}=1 / \hat{p}_{e}$ relative to the true outcome probability $\varphi_{e}$. If he deviates from the efficient price $s$ by $(+d s)$, he offers less favorable terms on this bet. At the same time, he then has to lower the price for the opposite wager by the same amount $(-d s)$.

We assume that betting volume on a particular outcome - at least within a range of $S_{e}=$ $[(s+d s),(s-d s)]$-is given by the following linear demand function

$$
S_{e}=\alpha-\beta V \text {. }
$$

The bookmaker can attract betting volume $V$ on the different outcomes by lowering his price $S_{e}$. This relation is moderated by the parameters $\alpha$ and $\beta$ describing the shape of the (individual) demand function the bookmaker is facing.

We now introduce sentimental-betting behavior. In a very simple way biased bettor preferences can be understood as a shift of the demand function to the upper right at the given price level $s$ for one of the outcomes relative to the other outcome. So, for a given profit margin asked by the bookmaker, there is more volume wagered by the betting audience on one of the outcomes compared to the other outcome. In our context, if the away team has a larger fan base than the home team, the demand for bets on the away team winning is increased due to a larger amount of sentimental betting, and the demand for the opposite bet attracting fewer sentiment bettors remains at the original level.

The optimal price-setting behavior in the presence of biased bettor preferences depends on the nature of the demand shift. The shift of demand can be induced by an increase of the intercept $\alpha+d \alpha$, by a decrease of the slope $\beta-d \beta$ or by a combination of the two. Hence, if there is sentiment betting, the demand function for bets on the team attracting more sentiment bettors $e \neq k$ takes the form

$$
S_{e \neq k}=(\alpha+d \alpha)-(\beta-d \beta) V,
$$

where $d \alpha \in[0, \infty[$ and $d \beta \in[0, \infty[$. An increase of the intercept $\alpha+d \alpha$ means that the additional demand is constant across different levels of prices. We will refer to this situation as the influence of priceinsensitive sentiment bettors. These bettors may wager on "their" team independent of the odds posted. They neither have a reservation price nor do they seek more favorable odds by comparing the prices of different bookmakers.

The influence of price-sensitive sentiment bettors is modeled by a decrease in slope $\beta-d \beta$ of the demand function. ${ }^{9}$ The interpretation of sentiment betting induced by $d \beta$ is the following: Some bettors may - on the basis of sentiment - choose a team on which to place a bet. In a

\footnotetext{
${ }^{9}$ Note that price elasticity of demand at a given reference price does not change if there is an increase of only pricesensitive sentiment bettors.
} 
second step they decide whether the odds on that team meets their reservation price. If they do not agree with the bookmaker's price, they may either not bet at all or switch to another bookmaker offering more favorable terms.

We now calculate the bookmaker's profit $\Omega_{d \alpha, d \beta}$ for the case where the bookmaker sets a price $(s+d s)$ for the sentiment bet and $(s-d s)$ for the opposite bet. According to Equation 2, the bookmaker's profit is given by the volume wagered times the corresponding price summed up for the two bets. We then derive the optimal deviation from the average price. The bookmaker's profit is maximized by an optimal price deviation $d s_{d \alpha, d \beta}^{*}$ solving

$$
\begin{aligned}
\max _{d s} \Omega_{d \alpha, d \beta}(s+d s)= & {\left[\frac{1}{\beta}+\frac{1}{\beta-d \beta}\right] s(\alpha-s)+\left[-\frac{1}{\beta}+\frac{1}{\beta-d \beta}\right] \alpha d s } \\
& -\left[-\frac{1}{\beta}+\frac{1}{\beta-d \beta}\right] 2 s d s+\frac{1}{\beta-d \beta} s d \alpha \\
& +\frac{1}{\beta-d \beta} d \alpha d s-\left[\frac{1}{\beta}+\frac{1}{\beta-d \beta}\right] d s^{2} .
\end{aligned}
$$

The first-order condition regarding $d s$ is

$$
\frac{\partial \Omega_{d \beta}}{\partial d s}=\left[-\frac{1}{\beta}+\frac{1}{\beta-d \beta}\right] \alpha-\left[-\frac{1}{\beta}+\frac{1}{\beta-d \beta}\right] 2 s+\frac{1}{\beta-d \beta} d \alpha-2\left[\frac{1}{\beta}+\frac{1}{\beta-d \beta}\right] d s=0 .
$$

Thus, the bookmaker's optimal price adjustment is given by

$$
d s_{d \alpha, d \beta}^{*}=\frac{1}{2} \frac{\left[-\frac{1}{\beta}+\frac{1}{\beta-d \beta}\right]}{\left[\frac{1}{\beta}+\frac{1}{\beta-d \beta}\right]}(\alpha-2 s)+\frac{1}{2} \frac{\left[\frac{1}{\beta-d \beta}\right]}{\left[\frac{1}{\beta}+\frac{1}{\beta-d \beta}\right]} d \alpha .
$$

If $d \alpha=0$ and $d \beta=0$, there is no sentiment toward any of the playing teams so that demand for home bets is equal to demand for away bets. In this case Equation 7 reduces to

$$
d s^{*}=0 .
$$

Hence, in this case the bookmaker should not deviate from the efficient price.

If $d \alpha>0$ and $d \beta=0$, sentiment is exclusively caused by price-insensitive bettors. Here, Equation 7 can be rearranged to

$$
d s_{d \alpha}^{*}=\frac{1}{4} d \alpha .
$$

Not surprisingly, the bookmaker should increase the price in the presence of only priceinsensitive sentiment bettors.

If $d \alpha=0$ and $d \beta>0$, sentiment betting is exclusively caused by price-sensitive bettors. In that case, Equation 7 reduces to

$$
d s_{d \beta}^{*}=\frac{1}{2} \frac{\left[-\frac{1}{\beta}+\frac{1}{\beta-d \beta}\right]}{\left[\frac{1}{\beta}+\frac{1}{\beta-d \beta}\right]}(\alpha-2 s) .
$$

Since the fraction is strictly positive, the direction to which the bookmaker should shade prices depends on the value of $(\alpha-2 s)$. The condition for a negative price deviation $d s_{d \beta}^{*}$ to be the 


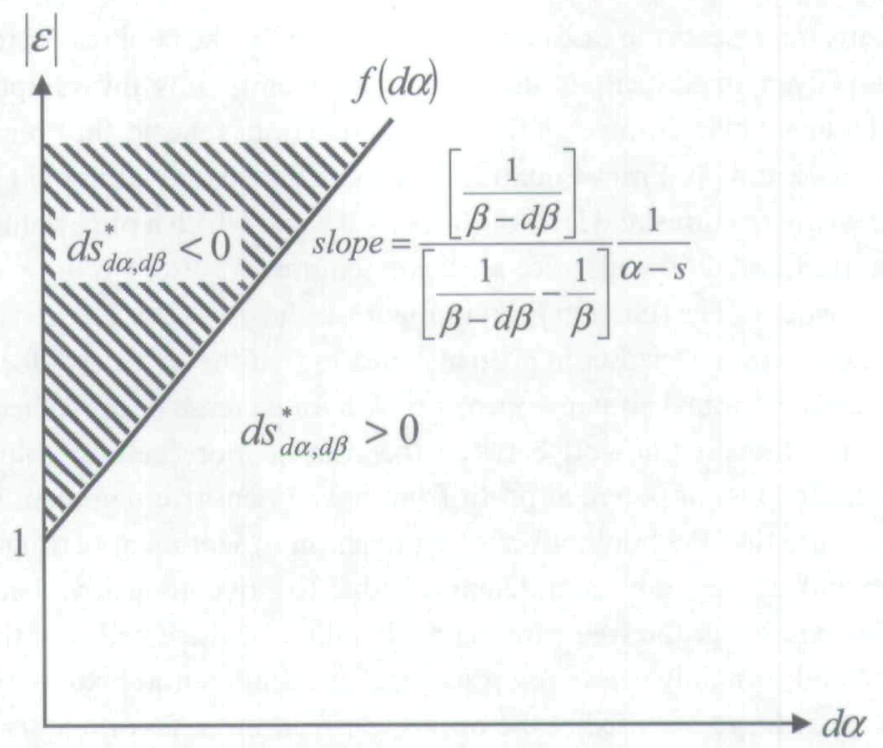

Figure 1. The bookmaker's price setting decision given sentiment betting denotes the elasticity of demand. The shaded area represents the cases where it is optimal for the bookmaker to lower the price for sentiment bets.

optimal choice is $(\alpha-2 s)<0$. This inequality can be rearranged to $s /(\alpha-s)>1$. In the case of a linear-demand function, the term on the left side is the absolute value of price elasticity of demand at the given price level $s$ defined as $|\varepsilon|=s /(\alpha-s)$. The condition for a negative price deviation $d s_{d \beta}^{*}$ to be optimal therefore reduces to

$$
d s_{d \beta}^{*}<0 \Leftrightarrow|\varepsilon|>1 \text {. }
$$

Hence, if sentiment betting is exclusively caused by price-sensitive bettors, the price should be decreased if the absolute value of elasticity of demand exceeds one. However, the bookmaker should increase the price if demand at the given reference price is inelastic, and the bookmaker should not deviate at all if demand is unit elastic.

Finally we examine the case of both price-insensitive sentiment bettors and price-sensitive sentiment bettors in the market. The optimal price deviation $d s_{d \alpha, d \beta}^{*}$ is negative if the condition

$$
(-1) \frac{\left[\frac{1}{\beta-d \beta}\right]}{\left[-\frac{1}{\beta}+\frac{1}{\beta-d \beta}\right]} d \alpha>(\alpha-2 s)
$$

is fulfilled. We can rearrange this inequality analogously to the previous case. The condition for a negative price deviation $d s_{d \alpha, d \beta}^{*}$ to be the optimal choice is then

$$
d s_{d \alpha, d \beta}^{*}<0 \Leftrightarrow|\varepsilon|>1+\frac{\left[\frac{1}{\beta-d \beta}\right]}{\left[-\frac{1}{\beta}+\frac{1}{\beta-d \beta}\right]} \frac{1}{\alpha-s} d \alpha .
$$

From Equation 13 we see that the optimal price adjustment depends on two characteristics of the demand function: the price elasticity of demand and the amount of price-sensitive sentiment bettors compared to price-insensitive sentiment bettors. Figure 1 illustrates the situation. 
The shaded area represents the cases where it is optimal for the bookmaker to lower the price for sentiment bets. Given an elasticity of demand $|\varepsilon|$ below unity, it is always optimal to increase the price for the sentiment bet. However, if the demand function is elastic, the optimal price-setting decision depends on $d \alpha$ and $d \beta$. From Equation 13 we can derive that additional price-insensitive bettors $(d \alpha>0)$ increase the threshold level of elasticity beyond which a price reduction maximizes the bookmaker's profit. Additional price-sensitive sentiment bettors $(d \beta>0)$ decrease the threshold level of elasticity. The function $f(d \alpha)$ in Figure 1 illustrates this relationship: The strictly positive slope of the function decreases in $d \beta$, which means that the "window" for lower prices on sentiment bets to be the optimal strategy opens up with an increase of $d \beta$. When decreasing the price, the bookmaker faces a trade-off between the gain of more betting volume from pricesensitive bettors and the loss of potential profit from price-insensitive sentiment bettors.

Our model implies that the bookmaker's best reaction to sentiment betting depends on the nature of the demand. If the additional demand is due to price-insensitive bettors, we expect less favorable odds relative to the true winning probability for these bets. On the other hand if the additional demand is mainly caused by price-sensitive sentimental bettors and overall price elasticity is sufficiently large, we predict the opposite effect: more favorable terms extended to sentiment bets.

\section{Empirical Evidence from the English Bookmaker Market}

In this section we examine the price effect of team popularity as one source of sentiment betting. The logic behind this kind of sentimental bettor preference is the idea that fans are unlikely to wager against the team they support due to loyalty toward "their" club. Thus, teams with comparatively larger fan bases are expected to attract more sentimental betting volume than less popular teams (see also Avery and Chevalier 1999; Forrest and Simmons 2008).

To test the influence of sentimental betting on the bookmaker's price-setting decision we analyze the odds on games in the upper four English soccer leagues played over eight seasons from 2000-2001 to 2007-2008. For each match online-betting odds from eight different bookmakers were collected from the webpage $w w w$ football-data.co.uk. The bookmakers are B365, BWin (BW), Gamebookers (GB), Interwetten (IW), Ladbrokes (LW), William Hill $(W H)$, Stan James (SJ), and VC Bet (VC). This list includes the two largest bookmakers in the UK, namely William Hill and Ladbrokes, but also smaller bookmakers like VC Bet. Since not all eight bookmakers offer odds on all soccer games of the upper-four English leagues, the sample size varies between 6107 and 16,024 matches.

As a proxy for the amount of sentiment bets that is caused by team popularity we use the average home attendance of a team during the previous season. Home attendance characterizes the active fan base: people who are willing to buy access to home matches. This figure is likely to correlate with the number of passive fans and, thus, potential sentiment bettors (Forrest and Simmons 2008). We collected the mean home attendance figures in the preceding season from the database www.european-football-statistics.co.uk. The numbers are standardized by dividing them by the given league's seasonal average. We then obtain $D A T T_{i}$, our proxy for the relative volumes of sentimental betting placed on the two teams competing on the field, by taking the difference between their standardized mean home attendances in the previous season.

Following our theoretical model, we concentrate on home and away win bets and ignore draw bets because they are not expected to be influenced by any sentiment toward one of the 
playing teams. We convert the listed "decimal odds" (e.g., 1.8) into "probability odds" $P R O B_{i}$, which are the reciprocal of the decimal odds $(1 / 1.8=0.56)$. The sum of the "probability odds" exceeds 1 by the bookmaker's over-round. Some studies like Forrest and Simmons (2008) therefore multiply the probability odds by $1 /(1+$ over-round $)$ to obtain the "implicit probabilities," which in turn sum up to one. The underlying assumption that the over-round is equally distributed over the three bets of a game seems questionable, however. In our model we argue that it is the posted odds, rather than the implicit margin-corrected probabilities, on which bettors base their decision whether to place a bet or not. For the punters it does not matter if odds are low due to the inherent over-round or as a result of distorted implicit probabilities. $^{10}$

In the theoretical model we have shown that the optimal price reaction of a profitmaximizing bookmaker depends on the elasticity of demand he is facing and how it is influenced by bettor sentiment. The European online-betting market in general and the English betting market in particular are highly competitive with numerous bookmakers and bet exchange platforms offering odds on the very same events (see, e.g., Paton, Siegel, Vaughan Williams 2010). Moreover, price transparency is high since bettors can easily compare the odds listed by several different bookmakers and find the best odds through a number of websites such as www.betexplorer.com or www.oddschecker.com. Therefore, we conjecture that additional sentimental demand is highly price sensitive. In line with the theoretical model we expect that English bookmakers decrease prices, that is, increase the odds of bets likely to attract a comparatively high sentimental betting volume. This implies that the posted odds of bets on very popular teams are under-priced and no longer reflect the observed winning probabilities.

We test this hypothesis by examining whether our proxy of sentiment betting renders some explanatory power to the true winning probabilities that lies beyond the bookmaker's probability odds. If this is the case the posted odds deviate from the efficient level at which each bet would be equally profitable on average. In particular we test a binary model that explains the actual outcome of a certain bet $Y_{i}$ ( 1 for a winning bet; 0 for a losing bet) in terms of the probability odds $P R O B_{i}$ and our sentiment proxy $D A T T_{i}$. In order to control for potential distortion of the probability odds related to home team factors rather than to the relative amounts of sentimental betting volume, we additionally include a control variable for home team bets $H O M E_{i}$ into the model. ${ }^{11}$ Table 1 illustrates the variables' summary statistics and the Pearson correlation coefficients.

We then estimate the following probit model, which explains the actual outcome of a certain bet $Y_{i} \in\{0,1\}$ in terms of the probability odds $P R O B_{i}$, our proxy for relative amounts of sentimental betting $D A T T_{i}$, and a dummy variable $H O M E_{i}$ for home team bets:

$$
Y_{i}=G\left(\beta_{1} P R O B_{i}+\beta_{2} D A T T_{i}+\beta_{3} H O M E_{i}+\epsilon_{i}\right) .
$$

\footnotetext{
${ }^{10}$ Our results react insensitively, however, if we estimate the model with margin-corrected, implicit probabilities.

${ }^{11}$ Our data sample includes two observations of the same match (the home win bet and the away win bet) for every bookmaker. As the independence assumption between these two observations is likely to be violated, we compute standard errors that are robust with respect to correlation of the error terms between the home win bet and the away win bet. In addition we experimented with a random selection of either a home or an away win bet per match, as well as separate regressions for only home or only away win bets to address the issue of nonindependence between observations within the same game. All three estimation procedures lead to virtually the same results.
} 
Table 1. Summary Statistics and Pearson Correlation Coefficients

\begin{tabular}{|c|c|c|c|c|c|c|c|c|c|}
\hline Variable & Description & Mean & $\begin{array}{l}\text { Standard } \\
\text { Deviation }\end{array}$ & Max & Min & 1 & 2 & 3 & 4 \\
\hline $1 Y_{i}$ & Actual outcome of bet $i(0 / 1)$ & 0.364 & 0.481 & 0.000 & 1.000 & 1.000 & & & \\
\hline $2 P_{R O B}$ & Probability odds & 0.409 & 0.145 & 0.048 & 0.935 & 0.289 & 1.000 & & \\
\hline $3 D_{A T T_{i}}$ & $\begin{array}{l}\text { Difference in attendance } \\
\text { figures }\end{array}$ & 0.000 & 0.599 & -2.621 & 2.621 & 0.132 & 0.393 & 1.000 & \\
\hline$H O M E_{i}$ & Home game dummy $(0 / 1)$ & 0.500 & 0.500 & 1.000 & 1.000 & 0.179 & 0.626 & 0.000 & 1.000 \\
\hline
\end{tabular}

This table shows the probability odds of the bookmaker William Hill, who is the largest bookmaker in the UK. The figures do not change much if any other of the eight bookmakers was chosen, because the correlations between sets of odds for each possible pair of bookmakers range from 0.98 to 0.99 . The variable $D A T T_{i}$ is calculated using the difference of the home attendance figures of the previous season standardized by season and league.

The probit model assumes a standard normal cumulative distribution of $G(.){ }^{12}$ The estimated marginal effects of the probit model, the levels of significance, and the standard errors (SE) are displayed in Table 2.

The results in Table 2 reveal that, controlling for the probability odds, the variable $D A T T_{i}$ significantly increases the likelihood that a bet will win. This implies that the probability odds $P R O B_{i}$ underestimate the frequency of wins by prestigious teams and overestimate the frequency of wins by less popular teams. Thus, more (less) favorable odds are offered to bettors of teams with a comparatively larger (lower) number of supporters. The null hypothesis of market efficiency is clearly rejected.

As a team's playing strength and popularity are correlated (the correlation between $P R O B_{i}$ and $D A T T_{i}$ is 0.393 , see Table 1), we have to be clear about the relationship between the sentiment bias and the well-known favorite longshot bias that refers to the observation that bookmaker odds underestimate high probability outcomes and overestimate low probability outcomes [for a review of the longshot bias literature, see Coleman (2004)]. So far we cannot rule out that our results are driven by Shin's longshot-bias explanation. Shin $(1991,1992,1993)$ pointed out that bookmakers tend to hedge against potential insiders with superior knowledge by increasing the prices (relative to true probabilities) where the risk is high, namely bets with high odds (longshot odds). Thus, a bookmaker may either increase the odds of the more popular team in order to attract sentimental-betting volume or, alternatively, the bookmaker may decrease the odds of the weaker team in order to secure against the risk of insider trading. Both lines of reasoning would yield similar empirical outcomes.

We use information regarding whether a game was played on a weekend rather than on weekdays to distinguish the sentiment bias from the longshot bias. The incidence of insider trading is likely to be uniformly distributed over the games and is therefore unrelated to the date of the game. Since teams are randomly assigned to play on weekdays, the risk of potential insider trading associated with the level of the posted odds is not correlated with the weekend dummy. Thus, the effect of playing on weekends is orthogonal to the longshot bias explanation of Shin (1991, 1992, 1993). The amount of sentimental betting, however, is expected to be more pronounced on weekends than on weekdays as the casual bettors face lower opportunity costs to place bets on weekends (Kopelman and Minkin 1991; Sobel and Raines 2003; Sung and

\footnotetext{
${ }^{12}$ Alternatively, we also tested the logit model and the linear probability model (LPM). The logit model assumes a logistic distribution and is, like the probit model, a nonlinear model, whereas the LPM is based on ordinary least squares and constant marginal effects. All three estimation procedures lead to virtually the same results.
} 
Table 2. Probit Estimates of the Sentiment Bias

\begin{tabular}{|c|c|c|c|c|c|c|c|c|}
\hline \multirow{2}{*}{$\begin{array}{l}\text { Dependent } \\
\text { Variable }\end{array}$} & \multicolumn{8}{|c|}{ Actual Outcome of Bet $i(0 / 1)$ by Bookmaker } \\
\hline & B365 & BW & GB & IW & LB & WH & SJ & $\mathrm{VC}$ \\
\hline$P R O B_{i}$ & $0.972 * * *$ & $0.941^{* * *}$ & $0.986^{* * * *}$ & $0.991 * * *$ & $0.947^{* * *}$ & $0.959 * * *$ & * $1.013^{* * *}$ & * $0.966 * * *$ \\
\hline & & & & $(0$ & $\begin{array}{r}0.03 \\
0.02\end{array}$ & $\begin{array}{l}(0.035) \\
0.022 * * *\end{array}$ & *.0.025* & 0.026 \\
\hline & $(0.007)$ & $(0.009)$ & & & $(0.007)$ & $(0.007)$ & $(0.011)$ & $(0.011)$ \\
\hline$H O M E_{i}$ & $\begin{array}{c}-0.004 \\
(0.011)\end{array}$ & $\begin{array}{c}-0.003 \\
(0.013)\end{array}$ & $\begin{array}{c}-0.001 \\
(0.009)\end{array}$ & $\begin{array}{c}0.008 \\
(0.009) \\
\end{array}$ & $\begin{array}{c}0.004 \\
(0.009) \\
\end{array}$ & $\begin{array}{c}0.007 \\
(0.009)\end{array}$ & $\begin{array}{r}-0.018 \\
(0.015)\end{array}$ & $\begin{array}{c}-0.007 \\
(0.015)\end{array}$ \\
\hline & 24,392 & $10,2 / 0$ & & 32,048 & 31,742 & 31,228 & 12,212 & 12,214 \\
\hline McFadden's $R^{2}$ & 0.062 & 0.061 & 0.066 & 0.064 & 0.064 & 0.079 & 0.062 & 0.061 \\
\hline
\end{tabular}

The table presents the marginal effects of multivariate probit regressions that explain the outcome of the bet with the probability implied by the odds of the bookmakers, the sentiment proxy, and the home team dummy. The SE are given in parentheses. In order to account for the nonindependence of observations of the same game, we compute SE that are robust with respect to correlation of error terms between the home win bet and the away win bet of the same game.

* Denotes significance at the $5 \%$ level.

** Denotes significance at the $1 \%$ level.

*** Denotes significance at the $0.1 \%$ level.

Johnson 2009). Analyzing greyhound betting, Sobel and Raines (2003) show that Friday and Saturday night races attract a larger share of casual bettors compared to weekday nights. On weekend races the average betting volume per person is much lower than on weekday races. Sung and Johnson (2009) argue that weekday bettors are more serious as they tend to have clear financial ambitions and invest more time, effort, and money in analyzing the investment decisions than the casual bettors on the weekends. The latter typically consider betting and watching the games or races as a leisure pursuit. As Kopelman and Minkin (1991) put it:

Weekday bettors tended to be serious: they apparently were importantly motivated by the desire for financial gain; and many appeared to be highly knowledgeable about their pursuits. In contrast, weekend bettors tended to be more casual; many apparently attended the track for entertainment or for social reasons: and many seemed to lack knowledge, making bets based on such (presumably) irrelevant factors as names, colours, and birthdates. (p. 701)

Hence, we argue that the casual bettors who are susceptible to all kinds of biases mostly wager on weekends when the opportunity costs are lower than on weekdays, whereas potential insider trading is unrelated to the day of the match. We therefore predict that the positive influence of the variable $D A T T_{i}$ on the likelihood of winning the bet is more pronounced on weekends than on weekdays. In Table 3 we first estimate the probit models for weekend games and weekday matches separately. To economize space, we only show the results of the four bookmakers with the highest coverage, including William Hill and Ladbrokes, the two biggest bookmakers in the UK. ${ }^{13}$

Whereas the proxy of a team's relative fan base does not affect the likelihood of winning the bet on weekdays, we find a strong and statistically significant positive influence for weekend games holding the probability odds constant.

In the next step we use the whole sample again but include a dummy marking weekend games as well as an interaction term between the proxy of sentimental betting and the weekend

${ }^{13}$ The results of the other four bookmakers not shown in Table 3 do not differ in any significant way, however. 
Table 3. Separate Probit Estimates of the Sentiment Bias for Weekday and Weekend Games

\begin{tabular}{|c|c|c|c|c|c|c|c|c|}
\hline \multirow{3}{*}{$\begin{array}{l}\text { Dependent } \\
\text { Variable }\end{array}$} & \multicolumn{8}{|c|}{ Actual Outcome of Bet $i(0 / 1)$ by Bookmaker } \\
\hline & \multicolumn{2}{|c|}{ Gamebooker } & \multicolumn{2}{|c|}{ Interwetten } & \multicolumn{2}{|c|}{ Ladbrokes } & \multicolumn{2}{|c|}{ William Hill } \\
\hline & Weekday & Weekend & Weekday & Weekend & Weekday & Weekend & Weekday & Weekend \\
\hline \multirow[t]{2}{*}{$P R O B_{i}$} & $1.010^{* * *}$ & * $0.978^{* * *}$ & $* 1.015^{* * *}$ & $0.983^{* * *}$ & $0.956^{* * *}$ & * $0.944 * * *$ & $0.988^{* * *}$ & * $0.948 * * *$ \\
\hline & $(0.066)$ & $(0.042)$ & $(0.070)$ & $(0.044)$ & $(0.067)$ & $(0.041)$ & $(0.067)-$ & -0.041 \\
\hline \multirow[t]{2}{*}{$D A T T_{i}$} & -0.006 & $0.027 * *$ & 0.002 & $0.037 * * *$ & 0.00001 & $0.029 * * *$ & 0.0004 & $0.030^{* * *}$ \\
\hline & $(0.013)$ & $(0.008)$ & $(0.012)$ & $(0.008)$ & $(0.012)$ & $(0.008)$ & $(0.013)$ & $(0.008)$ \\
\hline \multirow[t]{2}{*}{$H O M E_{i}$} & $-0.011-$ & -0.003 & 0.0004 & 0.010 & -0.002 & 0.007 & -0.002 & 0.010 \\
\hline & $(0.018)$ & $(0.011)$ & $(0.018)$ & $(0.011)$ & $(0.018)$ & $(0.011)$ & $(0.018)$ & $(0.011)$ \\
\hline Observations & 8510 & 22,212 & 8976 & 23,072 & 8698 & 23,044 & 8742 & 22,486 \\
\hline McFadden's $R^{2}$ & 0.061 & 0.061 & 0.060 & 0.066 & 0.059 & 0.067 & 0.063 & 0.068 \\
\hline
\end{tabular}

The table presents the marginal effects of multivariate probit regressions that explain the outcome of the bet with the probability implied by the odds of the bookmakers, the sentiment proxy, and the home team dummy separately for weekday and weekend games. The SE are given in parentheses. In order to account for the nonindependence of observations of the same game, we compute SE that are robust with respect to correlation of error terms between the home win bet and the away win bet of the same game.

* Denotes significance at the $5 \%$ level.

** Denotes significance at the $1 \%$ level.

*** Denotes significance at the $0.1 \%$ level.

dummy. The interaction term allows us to test the statistical significance of the moderating influence of the weekend dummy. As standard software does not estimate correct magnitudes and SE of interaction effects in nonlinear models (Ai and Norton 2003), we use the algorithm of Norton, Wang, and Ai (2004) to compute the correct marginal effect of the interaction term between the proxy of sentimental betting and the weekend dummy.

Table 4 reveals that the interaction effect is significantly positive for all bookmakers. Bookmakers decrease prices, that is, increase the odds of bets on more popular teams on the weekends when sentiment bettors face lower opportunity costs to wager. This positive weekend effect is not compatible with Shin's explanation of the longshot bias, but it is perfectly in line with our prediction concerning the optimal bookmaker's reaction to price-sensitive sentimental betting demand. ${ }^{14}$

In the following we assess the economic relevance of our empirical results. To this end, we calculate the average returns of a betting strategy that takes advantage of the bookmaker's price reaction due to sentimental-betting volume. We use the odds of William Hill, one of the dominant bookmakers in the English betting market. ${ }^{15}$ In line with our previous findings we expect a positive relation between the average observed returns and the variable $D A T T_{i}$. Simple descriptive statistics seem to support this hypothesis: Weekday bets from the top $10 \%$-quantile regarding $D A T T_{i}$ ( 868 bets in total) yield an average return of -0.081 compared to a normal return of -0.134 (the average of 8742 bets). On weekends the difference is more distinctive: Bets

\footnotetext{
${ }^{14}$ Of course we cannot rebut any other explanation why the bookmaker odds underestimate the frequency of highprobability outcomes. Some other authors argue with risk-loving (Ali 1977; Quandt 1986) and/or skewness-loving bettor preferences (Golec and Tamarkin 1998). Such sentimental-bettor preferences raise the demand of high odds (low-probability outcomes), which increases the price of the high odds and thus causes a longshot bias in pari-mutuel betting markets but not necessarily in the bookmaker market. Given the high price elasticity of demand in the English betting market, our model predicts that bookmakers would actually not increase but reduce the price of longshot odds to attract the sentimental-betting volume of risk-loving bettors. However, we do not see this in our data.

${ }^{15}$ The findings are similar using the odds of other bookmakers.
} 
Table 4. Interaction Effects of the Sentiment Proxy with the Weekend Dummy

\begin{tabular}{lccccccccc}
\hline & \multicolumn{7}{c}{ Actual Outcome of Bet $i(0 / 1)$ by Bookmaker } \\
\cline { 2 - 10 } Dependent Variable & B365 & BW & GB & IW & LB & WH & SJ & VC \\
\hline PROB $_{i}$ & $0.972^{* * *}$ & $0.940^{* * *}$ & $0.986^{* * *}$ & $0.992^{* * *}$ & $0.947^{* * *}$ & $0.959^{* * *}$ & $1.010^{* * *}$ & $0.964^{* * *}$ \\
& $(0.041)$ & $(0.050)$ & $(0.036)$ & $(0.037)$ & $(0.035)$ & $(0.035)$ & $(0.060)$ & $(0.058)$ \\
DATT $_{i} \times$ & $0.034^{*}$ & $0.043^{* *}$ & $0.028^{*}$ & $0.029^{*}$ & $0.026^{*}$ & $0.024^{*}$ & $0.053^{* *}$ & $0.055^{* *}$ \\
WEEKEND $_{i}$ & $(0.013)$ & $(0.017)$ & $(0.012)$ & $(0.012)$ & $(0.011)$ & $(0.012)$ & $(0.019)$ & $(0.019)$ \\
DATT $_{i}$ & -0.006 & -0.004 & -0.003 & 0.005 & 0.001 & 0.004 & -0.016 & -0.017 \\
& $(0.013)$ & $(0.016)$ & $(0.011)$ & $(0.011)$ & $(0.011)$ & $(0.011)$ & $(0.018)$ & $(0.018)$ \\
WEEKEND $_{i}$ & 0.007 & 0.010 & 0.007 & 0.006 & 0.005 & 0.006 & 0.008 & 0.009 \\
& $(0.005)$ & $(0.006)$ & $(0.004)$ & $(0.004)$ & $(0.004)$ & $(0.004)$ & $(0.007)$ & $(0.007)$ \\
HOME $_{i}$ & -0.005 & -0.004 & -0.001 & 0.008 & 0.004 & 0.007 & -0.018 & -0.007 \\
& $(0.011)$ & $(0.013)$ & $(0.010)$ & $(0.009)$ & $(0.009)$ & $(0.009)$ & $(0.015)$ & $(0.015)$ \\
\hline Observations & 24,394 & 16,270 & 30,722 & 32,048 & 31,742 & 31,228 & 12,212 & 12,214 \\
McFadden's $R^{2}$ & 0.062 & 0.061 & 0.084 & 0.064 & 0.065 & 0.066 & 0.063 & 0.062 \\
\hline
\end{tabular}

The table presents the marginal effects of multivariate probit regressions that incorporate an interaction term between the weekend dummy and the sentiment proxy. The marginal effects and the SE of the interaction terms are calculated by the algorithm of Norton, Wang, and $\mathrm{Ai}$ (2004). The SE are given in parentheses. In order to account for the nonindependence of observations of the same game, we compute SE that are robust with respect to correlation of error terms between the home win bet and the away win bet of the same game.

* Denotes significance at the $5 \%$ level.

** Denotes significance at the $1 \%$ level.

*** Denotes significance at the $0.1 \%$ level.

of the top $10 \%$-quantile regarding $\operatorname{DATT}_{i}$ (2242 bets) exhibit an average return of -0.044 , whereas the normal return is -0.119 (the average of 22,486 bets in total). To investigate the relation between the observed returns of the bets and the variable $D A T T_{i}$ over the whole range of $D A T T_{i}$, we plot the observed mean returns against different categories of $D A T T_{i}$. The categories are specified by a bandwidth of 0.05 of $D A T T_{i}$, and at least 100 observations per group are required. In addition we run a locally weighted polynominal regression (Fan 1992; Fan and Gijbels 1996). ${ }^{16}$ This nonparametric procedure offers the advantage that we do not have to make any assumption about the functional form of the relationship between the returns and $D A T T_{i}$. Figure 2 shows the results of this procedure for bets on weekdays, whereas Figure 3 illustrates the results for weekend bets.

Figures 2 and 3 show that the returns tend to increase with $D A T T_{i}$. The returns for the different categories of $D A T T_{i}$ (the dots) are above average (the broken horizontal line) for positive figures of $D A T T_{i}$ and below average for negative values of $D A T T_{i}$, and the local polynomial smoothing (the solid line) increases with $D A T T_{i}$. For weekend games this relation is stronger than for weekday games, at least in the range of $-0.5<D A T T_{i}<0.5$ (which includes more than $65 \%$ of all observations). These findings illustrate that the bookmaker's price reaction to sentimental bettor preferences is economically relevant as it enables above-average returns. However, it does not permit to beat the odds and to systematically earn positive returns.

\footnotetext{
${ }^{16}$ Local polynomial regression involves fitting the dependent variable, here the observed returns, to a polynomial form of the regressor $D A T T_{i}$ via locally weighted least squares. We estimate a local cubic polynomial weighted by the Epanechnikov kernel function. The amount of smoothing is controlled by a bandwidth chosen at 0.2 .
} 


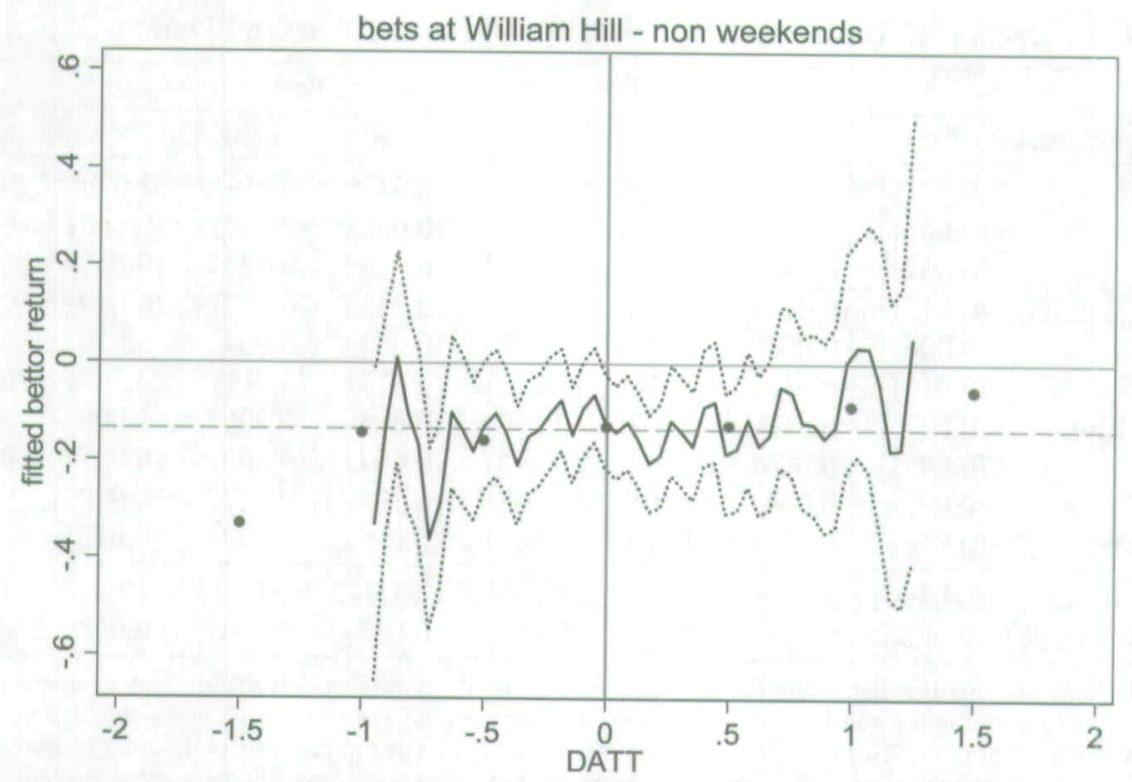

Figure 2. Observed mean return as a function of the sentiment proxy for weekday games. The lines are for zero return (solid horizontal line) and the expected return under random betting (broken line). The mean returns for the different categories of DATT (dots) and the local polynomial smoothing (solid line) with 95\% confidence intervals (dotted lines) are given.

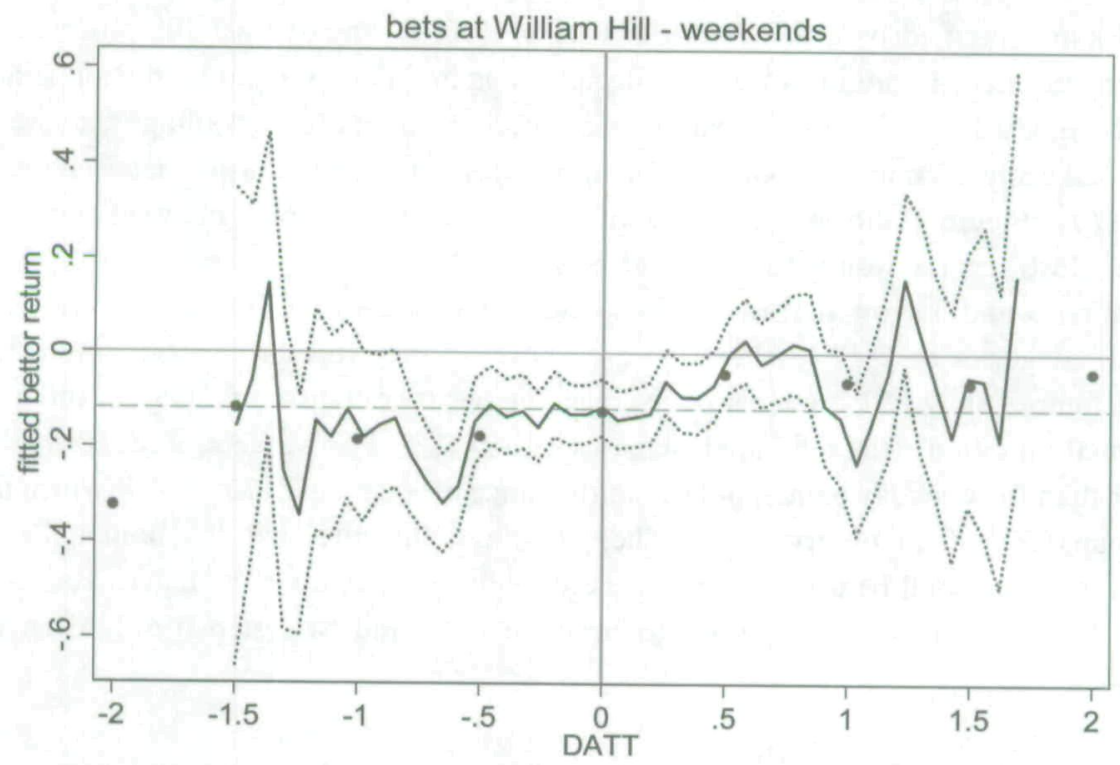

Figure 3. Observed mean return as a function of the sentiment proxy for weekend games. The lines are for zero return (solid horizontal line) and the expected return under random betting (broken line). The mean returns for the different categories of DATT (dots) and the local polynomial smoothing (solid line) with $95 \%$ confidence intervals (dotted lines) are given. 


\section{Conclusion}

Betting markets are characterized by the coexistence of different organizational settings. Customers can choose between the quote-driven setting and place a bet at a bookmaker or, alternatively, they can choose the order-driven setting and place a bet at the exchange market. Since bookmakers are exposed to substantial risk and incur significant transaction costs in calculating their quotes, the question arises why they are still able to survive against competition from exchange markets operating as mere platforms between bettors.

Among the more recent explanations of this puzzle is the general idea that the business model of bookmakers is based on actively managing quotes to exploit sentimental bettor preferences. The theoretical model presented in this article shows that the pricing decision of a profit-maximizing bookmaker depends on both the occurrence of bettor sentiment and the elasticity of demand he is facing. In particular the bookmaker will increase the price (i.e., decrease the odds) in the presence of price-insensitive sentiment bettors. If, however, the sentiment bettors are predominantly price-sensitive, the bookmakers can increase profits by lowering the price (i.e., increasing the odds) of bets on prestigious teams. As the English betting market is highly competitive with several bookmakers and bet exchanges offering odds on the same events, sentimental bettors are likely to be price-sensitive.

Using odds on more than 16,000 games in English soccer, we test the bookmaker's price reaction to the sentiment betting demand evoked by team popularity. We find that bookmakers significantly decrease the price of bets on team winnings with a large supporter base. In addition we find that this effect is amplified on weekends when sentimental bettors have lower opportunity costs to observe the games and place a wager. On weekend games the bookmaker offered significantly more favorable odds for bets on more heavily supported teams. Thus, bookmakers offer better prices to attract a larger share of the price-sensitive sentiment bettors. By taking a more in-depth look at the microeconomics of price-setting decisions, our article supports the general idea that economizing on the sentimental preferences of bettors plays an important role in the business model of bookmakers.

\section{References}

Ai, C., and E. C. Norton. 2003. Interaction terms in logit and probit models. Economics Letters 80:123-9.

Ali, M. 1977. Probability and utility estimates for racetrack bettors. Journal of Political Economy 85:805-15.

Avery, C., and J. Chevalier. 1999. Identifying investor sentiment from price paths: The case of football betting. Journal of Business 72:493-521.

Braun, S., and M. Kvasnicka. 2008. Against all odds? National sentiment and wagering on European football. Working paper. Ruhr Economic Paper No. 42.

Bruce, A. C., and J. E. V. Johnson. 2005. Market ecology and decision behaviour in state-contingent claims markets. Journal of Economic Behavior and Organization 56:199-217.

Chung, J., and J. H. Hwang. 2010. An empirical examination of the parimutual sports lottery market versus the bookmaker market. Southern Economic Journal 76:884-905,

Coleman, L. 2005. New light on the longshot bias. Applied Economics 36:315-26.

Dobson, S., and J. Goddard. 2001. The economics of football. Cambridge, UK: Cambridge University Press.

Fan, J. 1992. Design-adaptive nonparametric regression. Journal of the American Statistical Association 87:998-1004.

Fan, J., and I. Gijbels. 1996. Local polynomial modelling and its applications. London: Chapman \& Hall.

Forrest, D., and R. Simmons. 2001. Globalisation and efficiency in the fixed-odds soccer betting market. Working Paper, University of Salford.

Forrest, D., and R. Simmons. 2008. Sentiment in the betting market on Spanish football. Applied Economics 40:119-26. Franck, E., E. Verbeek, and S. Nüesch. 2010a. Inter-market arbitrage in betting. Working Paper. University of Zurich. 
Franck, E., E. Verbeek, and S. Nüesch. 2010b. Prediction accuracy of different market structures - Bookmakers versus a betting exchange. International Journal of Forecasting 26:448-59.

Golec, J., and M. Tamarkin. 1998. Bettors love skewness, not risk, at the horse track. The Journal of Political Economy 106:205-25.

Koning, R. H., and B. van Velzen. 2009. Betting exchanges: The future of sports betting? International Journal of Sports Finance 4:42-62.

Kopelman, R. E., and B. L. Minkin. 1991. Toward a psychology of parimutual behavior: Test of Gluck's laws. Psychological Reports 68:701-2.

Kuypers, T. 2000. Information and efficiency: An empirical study of a fixed odds betting market. Applied Economics 32:1353-63.

Levitt, S. 2004. Why are gambling markets organized so differently from financial markets? Economic Journal 114:223-46.

Madhavan, A. 2000. Market microstructure: A survey. Journal of Financial Markets 3:205-58.

Marshall, B. R., and M. Young. 2003. Liquidity and stock return in pure order-driven markets: Evidence from the Australian stock market. International Review of Financial Analysis 12:173-88.

Norton, E. C., H. Wang, and C. Ai. 2004. Computing interaction effects and standard errors in logit and probit models. Stata Journal 4:154-67.

Paton, D., D. S. Siegel, and L. Vaughan Williams. 2010. Gambling, prediction markets and public policy. Southern Economic Journal 76:878-83.

Pope, P., and D. Peel. 1989. Information, prices, efficiency in fixed-odds betting market. Economica 56:323-41.

Quandt, R. 1986. Betting and equilibrium. The Quarterly Journal of Economics 101:201-8.

Schwartz, R. A., and B. W. Weber. 1997. Next generation securities market systems: An experimental investigation of quote-driven and order-driven trading. Journal of Management Information Systems 14:57-79.

Shin, H. A. 1991. Optimal betting odds against insider traders. Economic Journal 101:1179 85.

Shin, H. A. 1992. Prices of state contingent claims with insider traders, and the favourite-longshot bias. Economic Journal 102:426-35.

Shin, H. A. 1993. Measuring the incidence of insider trading in a market for state-contingent claims. Economic Journal 103:1141-53

Smith, M. A., D. Paton, and L. Vaughan Williams. 2009. Do bookmakers possess superior skills in predicting outcomes? Journal of Economic Behavior and Organization 71:539-49.

Smith, M., D. Paton, and L. Vaughan Williams. 2006. Market efficiency in person-to-person betting. Economica 73:673-89.

Sobel, R. S., and T. Raines. 2003. An examination of the empirical derivatives of the favourite-longshot bias in racetrack betting. Applied Economics 35:371-85.

Sung, M., and J. E. V. Johnson. 2009. Evidence of a weekend effect in a market for state contingent claims. Working paper, University of Southhampton.

Verbeek, Erwin. 2009. Information Efficiency in Speculative Markets, Ph.D. Dissertation, University of Zurich.

Vlastakis, N., G. Dotsis, and R. Markellos. 2009. How efficient is the European football betting market? Evidence from arbitrage and trading strategies. Journal of Forecasting 28:426-44. 
Copyright of Southern Economic Journal is the property of Southern Economic Association and its content may not be copied or emailed to multiple sites or posted to a listserv without the copyright holder's express written permission. However, users may print, download, or email articles for individual use. 